\title{
Modern approaches to blood pressure measurement
}

\author{
Jan A Staessen, Eoin T O'Brien, Lutgarde Thijs, Robert H Fagard
}

\begin{abstract}
Background-Blood pressure (BP) is usually measured by conventional sphygmomanometry. Although apparently simple, this procedure is fraught with many potential sources of error. This review focuses on two alternative techniques of BP measurement: ambulatory monitoring and self measurement.

Review-BP values obtained by ambulatory monitoring or self measurement are characterised by high reproducibility, are not subject to digit preference or observer bias, and minimise the transient rise of the blood pressure in response to the surroundings of the clinic or the presence of the observer, the so called white coat effect. For ambulatory monitoring, the upper limits of systolic/diastolic normotension in adults include $130 / 80 \mathrm{~mm} \mathrm{Hg}$ for the 24 hour BP and $135 / 85$ and $120 / 70 \mathrm{~mm}$ $\mathrm{Hg}$ for the daytime BP and night time BP, respectively. For the the self measured $\mathrm{BP}$ these thresholds include $135 / 85 \mathrm{~mm} \mathrm{Hg}$.
\end{abstract} Automated BP measurement is most useful to identify patients with white coat hypertension. Whether or not white coat hypertension predisposes to sustained hypertension remains debated. However, outcome is better correlated with the ambulatory BP than with the conventional BP. In patients with white coat hypertension, antihypertensive drugs lower the $B P$ in the clinic, but not the ambulatory $B P$, and also do not improve prognosis. Ambulatory BP monitoring is also better than conventional BP measurement in assessing the effects of treatment. Ambulatory BP monitoring is necessary to diagnose nocturnal hypertension and is especially indicated in patients with borderline hypertension, elderly patients, pregnant women, patients with treatment resistant hypertension, and also in patients with symptoms suggestive of hypotension.

Conclusions-The newer techniques of BP measurement are now well established in clinical research, for diagnosis in clinical practice, and will increasingly make their appearance in occupational and environmental medicine.

(Occup Environ Med 2000;57:510-520)
Keywords: ambulatory blood pressure; self measurement; white coat hypertension

Blood pressure measurement, apparently a simple procedure, is of great relevance to occupational and environmental medicine. Some pollutants- such as lead ${ }^{1-3}$ or cadmium, ${ }^{4-6}$ - at exposure concentrations encountered at the workplace or in the environment, are suspected to increase blood pressure and to cause hypertension. Other studies showed that job strain, defined as high psychosocial demand and low decision latitude, correlated significantly and positively with hypertension. ${ }^{78}$ Furthermore, the medical examination of the work force, at the time of first employment or later at regular follow up intervals, commonly involves a measurement of blood pressure. Some jobs with much responsibility for the security of other people, require that from a cardiovascular perspective the applicant or employee is in good health and normotensive. Specialised hypertension clinics, therefore, often have to deal with referrals from occupational medical services to confirm or to refute the diagnosis of hypertension.

In most circumstances blood pressure is measured by conventional sphygmomanometry and by auscultation of the Korotkoff sounds. ${ }^{9}$ The past two decades have witnessed a growing awareness of the imperfection of the Korotkoff method. Newer techniques, such as ambulatory blood pressure monitoring ${ }^{10-12}$ and the self measurement of blood pressure ${ }^{13}$ are gradually gaining wide acceptance in clinical medicine to overcome some of the limitations of conventional sphygmomanometry. The goal of this review article is to put these newer approaches to blood pressure measurement into perspective.

\section{Limitations of conventional} sphygmomanometry

The measurement of blood pressure in clinical practice is dependent on the accurate transmission and interpretation of the arterial pulse wave and the Korotkoff sounds. The procedure is fraught with potential sources of error, which may arise in the subject, the observer, the sphygmomanometer, or in the overall application of the technique. ${ }^{14}{ }^{15}$ Even if all possible precautions are taken, the accuracy of 
non-invasive blood pressure measurement, in comparison with intra-arterial readings, remains imperfect. ${ }^{16}{ }^{17}$ The Korotkoff method tends to produce values for systolic blood pressure that are lower than the intra-arterial pressure, whereas the reverse is true for diastolic blood pressure without obvious superiority of phase V over phase IV. ${ }^{17}$

Systematic error in the sphygmomanometric measurement of blood pressure may be caused by lack of mental concentration, deteriorating auditory acuity, or failure to accurately interpret the Korotkoff sounds. ${ }^{18}$ Terminal digit preference refers to the phenomenon, whereby the observer rounds off the blood pressure reading to an arbitrary digit, often to a zero or a five. ${ }^{18}{ }^{19}$ Observer bias is the practice whereby the observer simply adjusts the blood pressure reading to meet a preconceived idea of what it should be. ${ }^{18}{ }^{20}$ Observer prejudice is most likely to occur when an arbitrary division line is applied to diagnose hypertension, to recruit patients, or to adjust treatment. ${ }^{20}$ Moreover, the presence of an observer-such as a nurse or a doctor-may arouse the patient and increase the blood pressure. ${ }^{21-25}$ This so called white coat phenomenon may lead to an overestimation of blood pressure, and hence to the artifactual diagnosis of hypertension. In patients with white coat hypertension, the seemingly increased blood pressure is not sustained in the absence of the observer. ${ }^{21-25}$

Another major drawback of conventional sphygmomanometry stems from the fact that blood pressure is highly variable, ${ }^{26}$ and as originally shown by researchers from Oxford, ${ }^{27}$ is characterised by large diurnal fluctuations. ${ }^{28}$ Single measurements or multiple readings taken by an auscultating observer at one or even several times through the day, reflect a subject's true blood pressure only to a minor extent. It is ironic that influential studies (for a review see Staessen et $a l^{\beta}$ ), which are viewed to support the hypothesis of a positive relation between hypertension and environmental lead

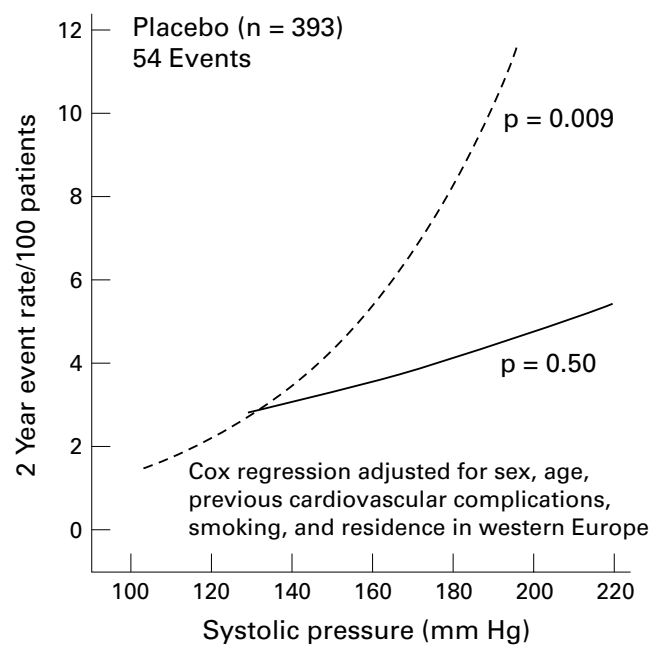

exposure, based their conclusions on blood pressure measurements at one examination or on a single blood pressure reading. ${ }^{29}{ }^{30}$ In other reports ${ }^{3}$ the blood pressure was measured in a non-standardised fashion or in exceptional circumstances, such as labour in pregnant women. ${ }^{31}$ The planners of the 3rd national health and nutrition examination survey $(1988-94)^{32}$ recognised this problem; in people aged 17 and over the seated blood pressure was measured three times at home and three times at mobile examination clinics.

A meta-analysis of nine prospective observational studies ${ }^{33}$ also highlighted the issue of regression dilution bias in assessing the correlations between disease outcomes and a risk factor-such as blood pressure. If the level is only measured on a single occasion, the results are biased by random fluctuation, so that the true association between a possible disease outcome and the usual blood pressure level (a person's long term mean blood pressure) is seriousy underestimated. ${ }^{33}{ }^{34}$ After correction for regression dilution bias, ${ }^{33}$ the slope of the relation (the relative risk for a given rise in blood pressure) steepens (fig 1). A reverse phenomenon may occur when in regression analysis blood pressure is the dependent variable and plotted, for instance, against age (fig 1) or body mass index. ${ }^{35}$

Ambulatory blood pressure measurement Ambulatory blood pressure monitoring makes it possible to record the blood pressure throughout the whole day in patients engaged in their normal activities and to provide within 24 hours a reliable estimate of their blood pressure. ${ }^{36}$ To collect the same information, conventional measurements must be repeated at intervals of a few weeks. ${ }^{37}$ Furthermore, the ambulatory blood pressure is characterised by high reproducibility, ${ }^{38}$ is not subject to digit preference and observer bias, ${ }^{20}$ and avoids the transient rise of a patient's blood pressure in response to the surroundings of the clinic or

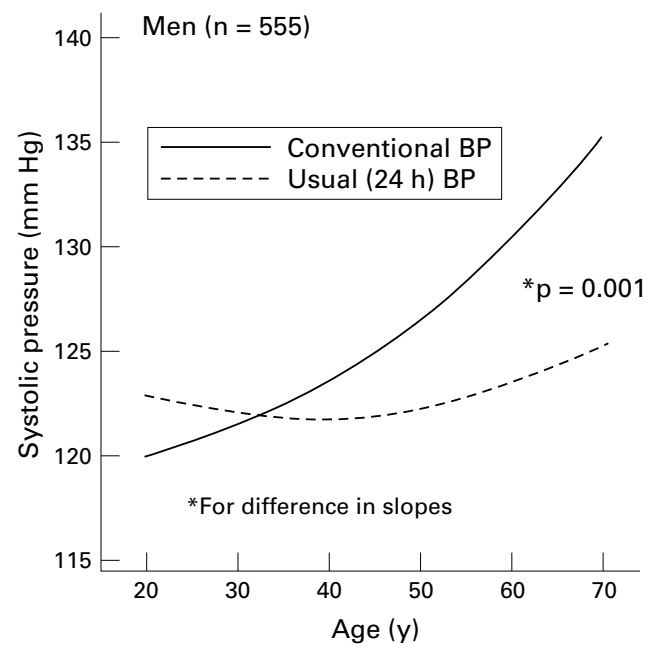

Figure 1 Plots involving the conventional and the usual blood pressures measured in the same people in each of two studies. ${ }^{35} 47$ The conventional blood pressure was the mean of two ${ }^{47}$ or five $e^{35}$ blood pressure readings at two separate examinations and the usual blood pressure was estimated by 24 hour ambulatory monitoring. If blood pressure is the independent variable, the slope of the relation is steeper for the usual than for the conventional blood pressure (left panel; regression dilution bias ${ }^{33}$; data from the placebo group ${ }^{47}$ ); the opposite occurs when blood pressure is the dependent variable (right panel; data from ${ }^{35}$ ). 
Table 1 The 95th percentiles as the upper limits of the distribution of the ambulatory blood pressure in normotensive subjects

\begin{tabular}{|c|c|c|c|c|c|c|c|}
\hline & $I D B$ & $A I B-S$ & Bel-PS & fap-PS & Dan-PS & It-PS & All \\
\hline References & 45.62 & 44 & 56 & 48.49 & 57 & 58 & \\
\hline \multicolumn{8}{|l|}{ Subjects: } \\
\hline All & 7320 & 815 & 1057 & 705 & 352 & 1438 & 11687 \\
\hline Normotensive subjects ${ }^{\star}$ & $3188+$ & 807 & 729 & $324 \ddagger$ & $238 \ddagger$ & 1402 & 5286 \\
\hline Mean (range) age (y) & $48(10-99)$ & $36(17-80)$ & $50(20-88)$ & $59(20-79)$ & $49(20-79)$ & $46(25-64)$ & $48(10-99)$ \\
\hline \multicolumn{8}{|l|}{ Systolic pressure $(\mathrm{mm} \mathrm{Hg})$ : } \\
\hline Conventional & 140 & 136 & 136 & 136 & 137 & 137 & 137 \\
\hline Whole day & 134 & 131 & 129 & 134 & 136 & 128 & 132 \\
\hline Daytime & 141 & 138 & 137 & 138 & 139 & 134 & 138 \\
\hline Night time & 128 & 120 & 121 & 128 & 122 & 121 & 123 \\
\hline \multicolumn{8}{|l|}{ Diastolic pressure $(\mathrm{mm} \mathrm{Hg})$ : } \\
\hline Clinic & 87 & 88 & 86 & 86 & 89 & 89 & 88 \\
\hline Whole day & 82 & 82 & 80 & 79 & 86 & 82 & 82 \\
\hline Daytime & 88 & 89 & 88 & 83 & 88 & 88 & 87 \\
\hline Night time & 77 & 72 & 72 & 74 & 77 & 74 & 74 \\
\hline
\end{tabular}

*95th percentiles were determined in normotensive subjects, with conventional blood pressure lower than $140 \mathrm{~mm} \mathrm{Hg}$ systolic and $90 \mathrm{~mm} \mathrm{Hg}$ diastolic.

†This group excludes participants of the Allied Irish Bank Study and the Belgian population study, who were analysed separately. $\ddagger$ For the Japanese and Danish studies, the authors provided the 95 th percentiles from the databases described in references 49 and 57 , respectively.

IDB=International database; AIB-S=Allied Irish Bank study; Bel-PS, Jap-PS, Dan-PS, It-PS=Belgian, Japanese, Danish, and Italian population studies, respectively.

the presence of the observer, ${ }^{24}$ the so called white coat effect. ${ }^{22} 39$

DEFINITION OF DIAGNOSTIC THRESHOLDS FOR AMBULATORY BLOOD PRESSURE MONITORING The association between blood pressure and cardiovascular risk is continuous without a threshold above which the risk suddenly increases. ${ }^{40}{ }^{41}$ However, clinical decisions must be based on diagnostic or operational thresholds. For ambulatory blood pressure monitoring, initially, these thresholds were largely based on the distribution of the ambulatory blood pressure in normotensive subjects and untreated hypertensive patients.

Firstly, several smaller studies described the ambulatory blood pressure in healthy subjects or in patients referred to specialised clinics to exclude the diagnosis of hypertension (for a review see Staessen et $a l^{42}$ ). In these reports the mean systolic blood pressure over the whole day ranged from 111 to $124 \mathrm{~mm} \mathrm{Hg}$; the daytime averages ranged from 115 to $128 \mathrm{~mm} \mathrm{Hg}$ and the night time means from 99 to $111 \mathrm{~mm}$ $\mathrm{Hg}$; the corresponding ranges for the diastolic blood pressure embraced 59 and $79 \mathrm{~mm} \mathrm{Hg}$, 63 and $85 \mathrm{~mm} \mathrm{Hg}$, and 51 and $70 \mathrm{~mm} \mathrm{Hg}$, respectively. ${ }^{42}$ Further epidemiological studies in well defined professional groups, ${ }^{43}{ }^{44}$ in normotensive and hypertensive subjects, ${ }^{42}{ }^{45-47}$ and in the population at large $e^{354-61}$ subsequently led to various proposals for normality of blood pressure on ambulatory measurement.

Table 2 Proposed thresholds for automated blood pressure measurements

\begin{tabular}{llll}
\hline & 95 th percentiles & Normotensiont & Hypertension $\neq$ \\
\hline Ambulatory blood pressure: & & & \\
24 h (mm Hg) & $132 / 82^{\star}$ & $\leqslant 130 / 80$ & $>135 / 85$ \\
Daytime (mm Hg) & $138 / 87^{\star}$ & $\leqslant 135 / 85$ & $>140 / 90$ \\
Night time (mm Hg) & $123 / 74^{\star}$ & $\leqslant 120 / 70$ & $>125 / 75$ \\
Self recorded blood pressure: & & & \\
Morning (mm Hg) & $136 / 85$ & $\leqslant 135 / 85$ & $>140 / 90$ \\
Evening (mm Hg) & $139 / 86$ & $\leqslant 135 / 85$ & $>140 / 90$ \\
Morning and evening (mm Hg) & $137 / 85$ & $\leqslant 135 / 85$ & $>140 / 90$ \\
\hline
\end{tabular}

${ }^{\star}$ Mean value for the 95 th percentiles in normotensive subjects (see table 1).

tObtained by rounding downward to the next blood pressure value ending in 0 or 5 .

† Obtained by rounding upward to the next value ending in 0 or 5 .
The most prominent feature of the larger studies on ambulatory monitoring 24454951 $525962-64$ is their striking concordance in the reported statistics, be it the mean plus two SDs (for a review see Staessen et $a l^{65}$ ) or the 95th percentile (table 1). Averaging the 95 th percentiles in the normotensive subjects and rounding the resulting boundaries downwards or upwards to the nearest value ending in 0 or 5 , may produce working definitions of normality for ambulatory monitoring, which can be easily remembered (table 2). The upper limits of normotension, calculated by rounding downwards, include $130 / 80 \mathrm{~mm} \mathrm{Hg}$ for the 24 hour blood pressure and 135/85 mm Hg and 120/70 $\mathrm{mm} \mathrm{Hg}$ for the daytime and night time blood pressures, respectively. Abnormality, obtained by rounding upwards, corresponds with blood pressures exceeding 135/85, 140/90, and $125 / 75 \mathrm{~mm}$ Hg. These preliminary threshold values did not account for sex and age. However, the boundaries currently in use for normotension and hypertension on conventional blood pressure measurement and jointly endorsed by the World Health Organisation/ International Society for Hypertension (WHO/ISH $)^{66}$ and the 6th report of the Joint National Committee on Prevention, Detection, Evaluation, and Treatment of High Blood Pressure (JNC VI), ${ }^{67}$-namely, $140 \mathrm{~mm} \mathrm{Hg}$ systolic and $90 \mathrm{~mm} \mathrm{Hg}$ diastolic-are also uniformly applicable to men and women and across all ages. Moreover, age correlates more strongly with the conventional than with the ambulatory blood pressure (fig 1, right panel). ${ }^{35} 4961$

VALIDATION OF THE DIAGNOSTIC THRESHOLDS IN TERMS OF LEFT VENTRICULAR HYPERTROPHY The diagnostic thresholds proposed in table 1 are supported by the prospective study of Verdecchia et al. ${ }^{68}$ Indeed, the boundaries proposed for the daytime blood pressure approximate to the cut off values of $136 / 87 \mathrm{~mm} \mathrm{Hg}$ in men and $131 / 86 \mathrm{~mm} \mathrm{Hg}$ in women, below which the incidence of cardiovascular events 
was the same in patients with white coat hypertension and normotensive subjects. ${ }^{68}$

Devereux et $a l^{69}$ contrasted the ambulatory measurements in normotensive subjects with normal left ventricular geometry with those in patients with concentric left ventricular hypertrophy, the morphological pattern associated with the worst prognosis. ${ }^{70}$ These investigators suggested that in awake adult men and women ambulatory blood pressures below 139/86 mm $\mathrm{Hg}$ may be considered normal, whereas values over 145/95 $\mathrm{mm} \mathrm{Hg}$ should be viewed as pathological ${ }^{69}$ Along similar lines, Gosse et $a l^{71}$ found that the left ventricular mass index increased with higher daytime blood pressure, but not with a larger white coat effect defined as the difference between the clinic and the daytime blood pressure. In the study of Gosse et $a l^{11}$ left ventricular mass index was on average not increased $\left(125 \mathrm{~g} / \mathrm{m}^{2}\right)$ in the patients in the bottom quartile of the daytime blood pressure, in whom during the day the systolic blood pressure ranged up to $133 \mathrm{~mm} \mathrm{Hg}$ and the diastolic up to $89 \mathrm{~mm} \mathrm{Hg}$.

VALIDATION OF THE DIAGNOSTIC THRESHOLDS FOR MORBIDITY AND MORTALITY

Perloff et al started the validation of ambulatory blood pressure monitoring in terms of hard cardiovascular end points. ${ }^{72}{ }^{73}$ These investigators used the patient activated Remler M-2000 recorder (Remler Corporation, San Fransisco, CA, USA). They showed for the first time that the portion of the daytime ambulatory blood pressure, which was not already explained by systolic or diastolic clinic blood pressure, could discriminate high risk from low risk hypertensive patients. ${ }^{72}$ These results obtained in 1076 hypertensive patients by life table analysis were later confirmed by Cox regression in a subgroup of 761 patients, who were untreated at baseline. ${ }^{73}$ With stratification for previous cardiovascular complications and with cumulative adjustments for clinic blood pressure, sex, age, electrocardiographic left ventricular hypertrophy, hypertensive retinopathy, and subsequent antihypertensive drug treatment, a higher systolic ambulatory blood pressure was still a harbinger of a worse cardiovascular outcome. ${ }^{73}$ Furthermore, a smaller study of 137 newly referred hypertensive patients showed that blood pressure, when measured intra-arterially over 24 hours, significantly increased the prognostic accuracy of conventional blood pressure readings. ${ }^{74}$ A recent report from the same centre included 479 patients who underwent 24 hour intra-arterial blood pressure monitoring and were followed up for an average of 9.1 years. ${ }^{75}$ White coat hypertension, defined as a clinic systolic blood pressure of $140-180 \mathrm{~mm} \mathrm{Hg}$ and a 24 hour blood pressure of less than $140 \mathrm{~mm} \mathrm{Hg}$ systolic and $90 \mathrm{~mm} \mathrm{Hg}$ diastolic, was present in 126 patients; compared with the patients with sustained hypertension $(n=353)$, white coat hypertensive patients had a $71 \%$ lower risk $(95 \%$ confidence interval (95\% CI) $10 \%-91 \%$; $\mathrm{p}=0.04$ ) of experiencing cardiovascular events. $^{75}$
Verdecchia et al followed up (mean 3.2 years) 1187 subjects with essential hypertension and 205 healthy normotensive control subjects, who all underwent baseline (off treatment) 24 hour non-invasive ambulatory blood pressure monitoring.$^{68}$ In the hypertensive patients the prevalence of white coat hypertension, defined as a mean daytime blood pressure lower than $136 / 87 \mathrm{~mm} \mathrm{Hg}$ in men and $131 / 86 \mathrm{~mm} \mathrm{Hg}$ in women, was $19.2 \%$. After adjustment for traditional markers of cardiovascular risk, morbidity did not differ between the normotensive subjects and the group with white coat hypertension $(p=0.83) .{ }^{68}$ Recently, Ohkubo et al found 1542 residents of a rural Japanese community, aged 40 years and over, in that their 24 hour systolic and diastolic blood pressures were significantly and curvilinearly correlated with total mortality. ${ }^{76}$ This second order relation persisted after cumulative adjustments for sex, age, smoking, use of antihypertensive medication at baseline and history of cardiovascular disease, diabetes, and hypercholesterolaemia. It also persisted after further adjustment for the conventional blood pressure at baseline and if the non-cardiovascular deaths were excluded from the analysis. ${ }^{77}$ Furthermore, Redon et al studied patients with refractory hypertension, defined as a diastolic blood pressure of more than $100 \mathrm{~mm} \mathrm{Hg}$, while taking three or more antihypertensive drugs. ${ }^{78}$ Patients were classified into three groups according to their daytime ambulatory blood pressure; those in the lowest tertile $(<88 \mathrm{~mm}$ $\mathrm{Hg}$ ) had a significantly lower rate of morbidity over the next 4 years than those in the middle $(88-97 \mathrm{~mm} \mathrm{Hg})$ or highest $(>97 \mathrm{~mm} \mathrm{Hg}$ ) tertiles. No differences in clinic blood pressure were found between these three groups either at baseline or at the time of the last evaluation. ${ }^{78}$

In a substudy ${ }^{4980}$ to the double blind placebo controlled systolic hypertension in Europe (Syst-Eur) trial, ${ }^{81}{ }^{82}$ the prognostic significance of conventional and ambulatory blood pressure measurement was compared in older patients with isolated systolic hypertension. The conventional blood pressure at randomisation was the mean of six readings (two measurements in the sitting position at three visits 1 month apart). The baseline ambulatory blood pressure was recorded with a non-invasive intermittent technique. Older ( $\geqslant 60$ years) patients whose untreated blood pressure on conventional measurement at baseline was $160-219 \mathrm{~mm} \mathrm{Hg}$ systolic and less than $95 \mathrm{~mm} \mathrm{Hg}$ diastolic, were randomised to nitrendipine (10-40 $\mathrm{mg} /$ day) with the possible addition of enalapril (5-20 $\mathrm{mg} /$ day) or hydrochlorothiazide $(12.5-25 \mathrm{mg} /$ day) or both, or to matching placebos. ${ }^{81} \mathrm{With}$ cumulative adjustments applied for sex, age, previous cardiovascular complications, smoking, and residence in western Europe, ${ }^{83}$ higher systolic blood pressure at randomisation predicted a worse prognosis (fig 2), whereas the association between diastolic blood pressure and outcome was not significant. ${ }^{47}$ In the placebo group ( $n=393$ ), the 24 hour, daytime (1000 to 2000), and night time (0000 to 0600) systolic ambulatory blood pressure predicted the incidence of cardiovascular complications even after 


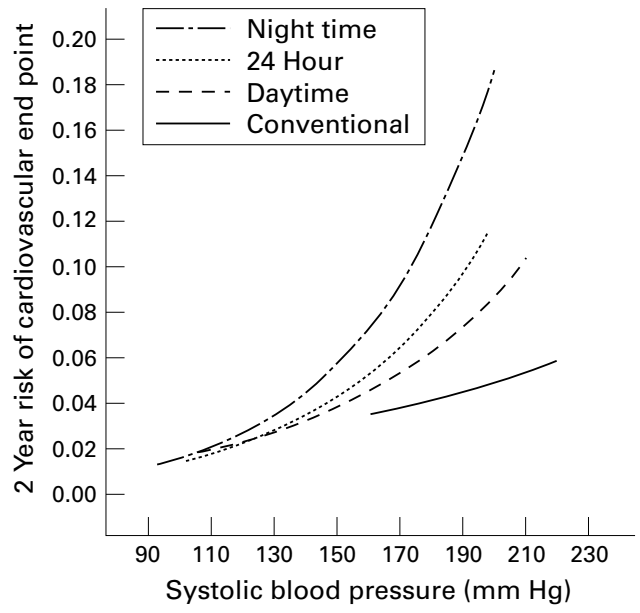

Figure 2 Systolic blood pressure on conventional, 24 hour, daytime, and night time measurement at randomisation as predictors of the 2 year incidence of cardiovascular end points in the 393 patients of the systolic hypertension in Europe (Syst-Eur) trial randomised to placebo. The Cox's models were standardised to female sex, 69.6 years (mean age), no previous cardiovascular complications, non-smoking, and residence in western Europe. Reproduced with permission from Staessen et al. ${ }^{47}$

further adjustment for the conventional blood pressure. ${ }^{47}$ At randomisation, the cardiovascular risk conferred by a conventional systolic blood pressure of $160 \mathrm{~mm} \mathrm{Hg}$ was similar to that associated with a 24 hour, daytime, or night time systolic blood pressure of $142 \mathrm{~mm} \mathrm{Hg}, 145 \mathrm{~mm}$ $\mathrm{Hg}$, or $132 \mathrm{~mm} \mathrm{Hg}$, respectively (fig 2). ${ }^{47}$ In the active treatment group $(\mathrm{n}=415)$, systolic blood pressure at randomisation did not significantly predict cardiovascular risk, regardless of the technique of blood pressure measurement. This finding confirmed that active treatment had reduced the excess risk conferred by hypertension.

\section{Diagnosis and treatment of white coat hypertension}

AMBULATORY BLOOD PRESSURE MONITORING FOR THE DIAGNOSIS OF HYPERTENSION

According to several sets of guidelines, ${ }^{66} 6784$ ambulatory blood pressure monitoring is most clinically helpful and most commonly used to identify patients with white coat hypertension (table 3). The prevalence of clinic hypertension in industrialised countries is nearly $15 \%$ of the adult population and may exceed $30 \%$ in those older than $70 .{ }^{85}$ Among patients with clinic hypertension, the prevalence of white coat hypertension varies from $15 \%^{22}{ }^{86}$ to $35 \%{ }^{45}$ depending on definitions.

The diagnosis of hypertension most often implies lifelong medical treatment. In patients

Table 3 Indications for ambulatory blood pressure monitoring

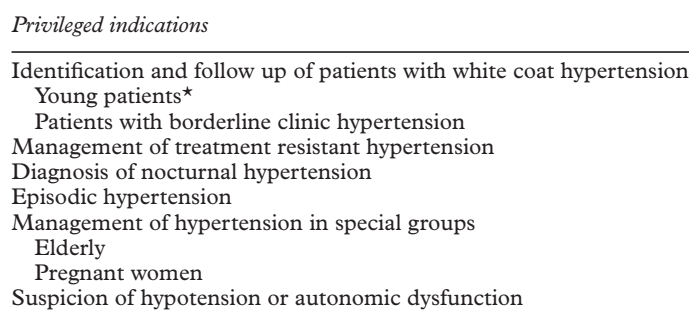

${ }^{\star}$ In particular patients undergoing a medical check up when applying for a job or insurance policy. with white coat hypertension who have no signs of target organ damage, antihypertensive drug treatment may be postponed or avoided by the use of ambulatory blood pressure monitoring. ${ }^{87}$ In view of the high prevalence of white coat hypertension, even if the clinic blood pressure is measured repeatedly at consecutive visits, ${ }^{47}$ ambulatory blood pressure monitoring, or an equivalent method of detecting the white coat syndrome, should become part of the routine investigation of all patients with suspected hypertension, in particular in those clinical centres, where sufficient resources and expertise are available to implement these techniques. Ambulatory blood pressure monitoring is especially indicated in patients with only a borderline increase of their clinic blood pressure in whom the prevalence of white coat hypertension may be as high as $60 \%-80 \%$, as well as in young subjects in whom lifelong drug treatment may be inappropriately prescribed and who may be penalised for insurance or employment if misdiagnosed as hypertensive (table 3).

Ambulatory blood pressure monitoring is itself not completely free from the white coat syndrome. Indeed, the initial few measurements on the ambulatory recorder and the final readings constitute the white coat window, reflect the patient's attention to attaching and removing the monitoring device in a medical environment and are often abnormally increased. ${ }^{88}$ Recent findings suggest that an increase in the ambulatory blood pressure above $140 \mathrm{~mm} \mathrm{Hg}$ systolic and $90 \mathrm{~mm} \mathrm{Hg}$ diastolic in the first or last hour of monitoring makes it possible to diagnose the white coat phenomenon independent of the clinic blood pressure and to identify a white coat hypertensive group with markedly increased clinic blood pressures and higher electrocardiographic Solokow-Lyon ${ }^{89}$ voltage indexes. ${ }^{88}$

\section{IS WHITE COAT HYPERTENSION REALLY}

INNOCENT?

A key issue for clinicians is to know how to deal with so called white coat hypertensive patients. Patients with white coat hypertension not only show greater blood pressure variability than normal control subjects, but also have a different metabolic and neuroendocrine profile. ${ }^{90}$ Some investigators reported that patients with white coat hypertension have moderately increased left atrial dimension ${ }^{91}$ and left ventricular mass, ${ }^{88} 91$ disturbed diastolic function of the left ventricle ${ }^{91}$ or an increased prevalence of silent coronary ischaemia. ${ }^{92}$ On the other hand, there is mounting evidence (already discussed) that apart from the few cases misclassified at initial diagnosis, outcome is better correlated with ambulatory blood pressure measurements than with clinic readings ${ }^{476872-7678}$ and that white coat hypertension, therefore, is genuinely a benign condition. In the Syst-Eur trial, ${ }^{47}$ to avoid problems with definitions and nomenclature, ${ }^{93}$ the white coat effect was analysed as a continuous variable; the risk conferred by any level of conventional systolic blood pressure at entry declined by nearly one 
fifth for each $10 \mathrm{~mm} \mathrm{Hg}$ increase in the white coat effect.

HOW TO DEAL WITH WHITE COAT HYPERTENSION The ambulatory blood pressure monitoring and treatment of hypertension (APTH) trial $^{87}{ }^{97}$ showed that adjustment of antihypertensive treatment based on ambulatory blood pressure monitoring instead of conventional sphygmomanometry may lead to less intensive drug treatment (fig 3) with preservation of blood pressure control, general wellbeing, and inhibition of left ventricular enlargement. Antihypertensive drug treatment may be postponed in $25 \%$ of the hypertensive patient population and multiple drug treatment may be avoided in $15 \%$.

The APTH results ${ }^{87}$ do not imply that patients with white coat hypertension should be left untreated. However, if no cardiovascular complications are present at diagnosis, treatment could be limited to further follow up and the implementation of cardiovascular hygienic measures - such as regular exercise, reduction of excessive alcohol and sodium intake, and weight reduction. ${ }^{98}$ Initial treatment should also account for other cardiovascular risk factors - such as smoking, hypercholesterolaemia, and diabetes mellitus. Whether or not patients with white coat hypertension are at higher risk of developing sustained hypertension remains debated. ${ }^{99}{ }^{100}$ For this reason, once white coat hypertension has been diagnosed, ambulatory blood pressure monitoring should be repeated at annual or biannual intervals.

\section{Management of treatment resistant hypertension}

Ambulatory blood pressure monitoring is not only better than conventional sphygmomanometry in selecting patients for antihypertensive drug treatment, but also in assessing the effects of such treatment. Two studies ${ }^{101102}$ showed that changes in ambulatory blood pressure correlated more closely with

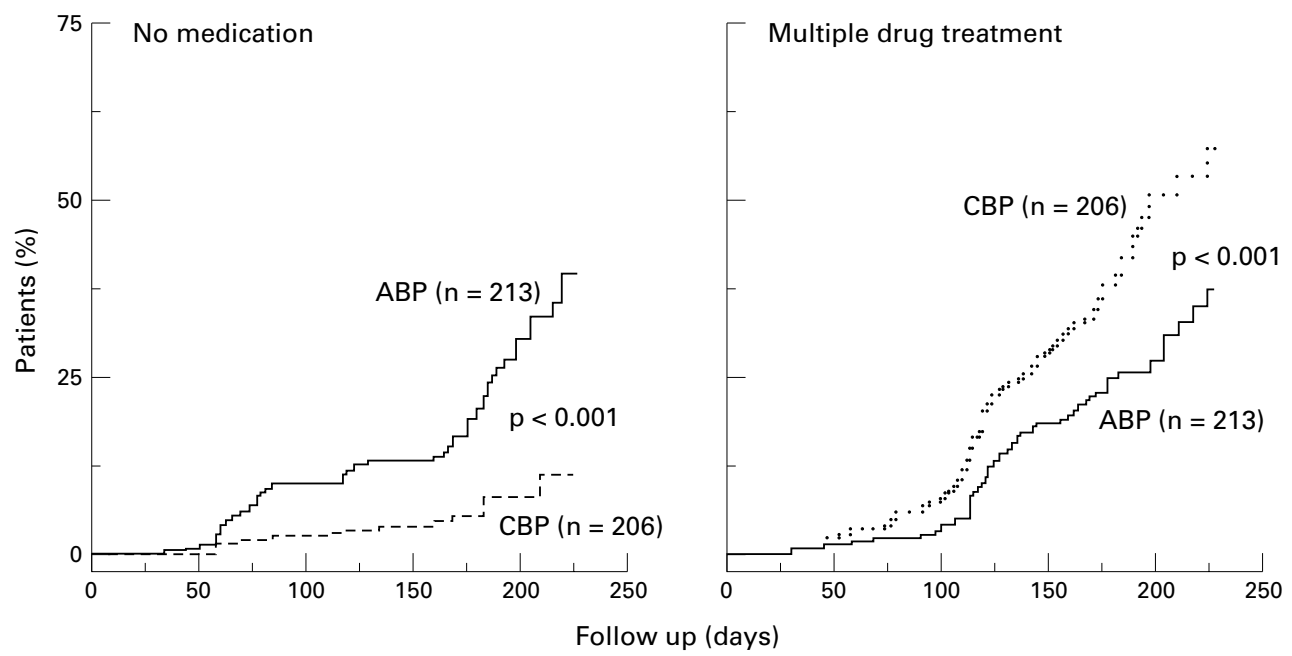

Figure 3 Kaplan-Meier estimates modelling the probability that during follow up patients would permanently stop antihypertensive drug treatment or would proceed to sustained multiple drug treatment. The differences between the patients randomised to conventional (CBP, broken line) or ambulatory (ABP, full line) blood pressure measurement were significant $(p<0.001)$. Reproduced with permission from Staessen et al. ${ }^{87}$ regression of left ventricular hypertrophy than did the changes in conventional blood pressure. In patients with white coat hypertension, antihypertensive medications lower the clinic but not the ambulatory blood pressure. ${ }^{94-96}$ Ambulatory monitoring is therefore an excellent technique to evaluate treatment resistant hypertension (table 3). According to the JNC VI guidelines, ${ }^{67}$ other indications for ambulatory monitoring are: hypotensive symptoms under antihypertensive drug treatment, episodic hypertension, and autonomic dysfunction. ${ }^{103}$

The current guidelines do not provide recommendations on the frequency with which ambulatory blood pressure monitoring should be repeated in hypertensive patients on medical treatment. If the initial evaluation shows the absence of a white coat phenomenon, then periodic clinic measurements may be adequate. As in patients with white coat hypertension, in clinical centres where sufficient resources can be allocated, an interval of 1 to 2 years between consecutive recordings seems reasonable, unless there is a special indication for more frequent recordings. ${ }^{98}$ The ambulatory blood pressure readings taken when on treatment should be below the thresholds applied for diagnosing sustained hypertension.

\section{Diagnosis of nocturnal hypertension}

Ambulatory blood pressure monitoring makes blood pressure measurement during sleep possible (table 3 ). The hypothesis that nondipping would be associated with greater cardiovascular risk $^{104}$ is not yet generally accepted, ${ }^{105}$ although there is accumulating evidence that the night time blood pressure may provide important prognostic information. ${ }^{468}$ Poor reproducibility of the dipping status ${ }^{50}$ and the use of varying definitions for non-dipping ${ }^{59}$ have contributed to the controversy.

To avoid the use of arbitrary thresholds, the Syst-Eur investigators analysed the night to day blood pressure ratio as a continuous variable. ${ }^{47}$ 
They found that the relative hazard rates associated with a $10 \mathrm{~mm} \mathrm{Hg}$ increase in the 24 hour systolic blood pressure and with a $10 \%$ higher night to day systolic blood pressure ratio were $1.23(95 \%$ CI 1.03 to $1.46 ; \mathrm{p}=0.02)$ and 1.41 ( $95 \%$ CI 1.03 to $1.94 ; \mathrm{p}=0.03$ ), respectively. Thus, the hypothesis of an inverse association between cardiovascular risk and blood pressure dipping at night was confirmed. ${ }^{104}$ Also, the night time blood pressure behaved as a more consistent predictor of major end points than the daytime blood pressure. The variability due to physical activity and psychoemotional stress may weaken the predictive power of the daytime blood pressure, whereas the greater uniformity resulting from sleeping may help to show correlations with the night time blood pressure. The finding that the mean (SD)

Table 4 Ambulatory blood pressure measuring devices which have been subjected to validation by the $B H S^{157}$ and $A A M I^{163}$ protocols

\begin{tabular}{|c|c|c|c|c|}
\hline Device & Mode & Circumstance & $A A M I+$ & $B H S \ddagger$ \\
\hline Accutracker II & Aus & At rest & $\mathrm{P} / \mathrm{P}$ & $\mathrm{A} / \mathrm{C}$ \\
\hline CH-DRUCK (103) & Aus & At rest & $\mathrm{P} / \mathrm{P}$ & $\mathrm{A} / \mathrm{A}$ \\
\hline Daypress 500 & Osc & At rest & $\mathrm{P} / \mathrm{P}$ & $\mathrm{A} / \mathrm{B}$ \\
\hline DIASYS 200 & Aus & At rest & $\mathrm{P} / \mathrm{P}$ & $\mathrm{C} / \mathrm{C}$ \\
\hline \multirow[t]{2}{*}{ DIASYS Integra } & Aus & At rest & $\mathrm{P} / \mathrm{P}$ & $\mathrm{B} / \mathrm{A}$ \\
\hline & Osc & At rest & $\mathrm{P} / \mathrm{P}$ & $\mathrm{B} / \mathrm{B}$ \\
\hline \multirow[t]{2}{*}{ ES-H531 } & Aus & At rest & $\mathrm{P} / \mathrm{P}$ & $\mathrm{A} / \mathrm{A}$ \\
\hline & Osc & At rest & $\mathrm{P} / \mathrm{P}$ & $\mathrm{B} / \mathrm{B}$ \\
\hline Medilog ABP & Aus & At rest & $\mathrm{P} / \mathrm{P}$ & \\
\hline Meditech ABPM-04 & Osc & At rest & $\mathrm{P} / \mathrm{P}$ & $\mathrm{B} / \mathrm{B}$ \\
\hline Nissei DS-240 & Osc & At rest & $\mathrm{P} / \mathrm{P}$ & $\mathrm{B} / \mathrm{A}$ \\
\hline OSCILL-IT & Osc & At rest & $\mathrm{P} / \mathrm{P}$ & $\mathrm{C} / \mathrm{B}$ \\
\hline Pressurometer IV & Aus & At rest & $\mathrm{F} / \mathrm{F}$ & $\mathrm{C} / \mathrm{D}$ \\
\hline \multirow[t]{2}{*}{ Profilomat } & Aus & At rest & $\mathrm{P} / \mathrm{P}$ & $\mathrm{B} / \mathrm{A}$ \\
\hline & & In pregancy & $\mathrm{P} / \mathrm{P}$ & $\mathrm{B} / \mathrm{C}$ \\
\hline Profilomat II & Osc & At rest & $\mathrm{F} / \mathrm{F}$ & $\mathrm{C} / \mathrm{B}$ \\
\hline \multirow[t]{9}{*}{ QuietTrak } & Aus & At rest & $\mathrm{P} / \mathrm{P}$ & $\mathrm{B} / \mathrm{B}$ \\
\hline & & & $\mathrm{P} / \mathrm{P}$ & $\mathrm{A} / \mathrm{A}$ \\
\hline & & Different posture & & $\mathrm{A} / \mathrm{A}$ \\
\hline & & During exercise & & $\mathrm{A} / \mathrm{A}$ \\
\hline & & In children & & $\mathrm{A} / \mathrm{A}$ \\
\hline & & In the elderly & & $\mathrm{A} / \mathrm{A}$ \\
\hline & & In pregnancy & $\mathrm{F} / \mathrm{F}$ & $\mathrm{B} / \mathrm{B}$ \\
\hline & & & & $\mathrm{A} / \mathrm{A}$ \\
\hline & & In pre-eclampsia & $\mathrm{F} / \mathrm{F}$ & $\mathrm{D} / \mathrm{D}$ \\
\hline Save 33 Model 2 & Osc & At rest & $\mathrm{P} / \mathrm{P}$ & $\mathrm{B} / \mathrm{B}$ \\
\hline \multirow[t]{2}{*}{ Schiller BR-102 } & Aus & Passed & $\mathrm{P} / \mathrm{P}$ & $\mathrm{B} / \mathrm{B}$ \\
\hline & Osc & Failed & $\mathrm{P} / \mathrm{P}$ & $\mathrm{B} / \mathrm{B}$ \\
\hline SpaceLabs 90202 & Osc & At rest & $\mathrm{P} / \mathrm{P}$ & $\mathrm{B} / \mathrm{B}$ \\
\hline \multirow[t]{9}{*}{ SpaceLabs 90207} & Osc & At rest & $\mathrm{P} / \mathrm{P}$ & $\mathrm{B} / \mathrm{B}$ \\
\hline & & In children & $\mathrm{P} / \mathrm{F}$ & $\mathrm{C} / \mathrm{D}$ \\
\hline & & In elderly people (different posture) & $\mathrm{P} / \mathrm{P}$ & $\mathrm{A} / \mathrm{C}$ \\
\hline & & In pregnancy & $\mathrm{P} / \mathrm{P}$ & $\mathrm{A} / \mathrm{C}$ \\
\hline & & & $\mathrm{P} / \mathrm{P}$ & $\mathrm{B} / \mathrm{B}$ \\
\hline & & & $\mathrm{P} / \mathrm{P}$ & $\mathrm{B} / \mathrm{C}$ \\
\hline & & In pre-eclampsia & $\mathrm{F} / \mathrm{F}$ & $\mathrm{D} / \mathrm{D}$ \\
\hline & & & $\mathrm{P} / \mathrm{P}$ & $\mathrm{C} / \mathrm{C}$ \\
\hline & & During haemodialysis & $\mathrm{P} / \mathrm{P}$ & $\mathrm{C} / \mathrm{B}$ \\
\hline SpaceLabs 90217 & Osc & At rest & $\mathrm{P} / \mathrm{P}$ & $\mathrm{A} / \mathrm{A}$ \\
\hline \multirow[t]{9}{*}{ SpaceLabs 90207} & Osc & At rest & $\mathrm{P} / \mathrm{P}$ & $\mathrm{B} / \mathrm{B}$ \\
\hline & & In children & $\mathrm{P} / \mathrm{F}$ & $\mathrm{C} / \mathrm{D}$ \\
\hline & & In elderly people (different posture) & $\mathrm{P} / \mathrm{P}$ & $\mathrm{A} / \mathrm{C}$ \\
\hline & & In pregnancy & $\mathrm{P} / \mathrm{P}$ & $\mathrm{A} / \mathrm{C}$ \\
\hline & & & $\mathrm{P} / \mathrm{P}$ & $\mathrm{B} / \mathrm{B}$ \\
\hline & & & $\mathrm{P} / \mathrm{P}$ & $\mathrm{B} / \mathrm{C}$ \\
\hline & & In pre-eclampsia & $\mathrm{F} / \mathrm{F}$ & $\mathrm{D} / \mathrm{D}$ \\
\hline & & & $\mathrm{P} / \mathrm{P}$ & $\mathrm{C} / \mathrm{C}$ \\
\hline & & During haemodialysis & $\mathrm{P} / \mathrm{P}$ & $\mathrm{C} / \mathrm{B}$ \\
\hline SpaceLabs 90217 & Osc & At rest & $\mathrm{P} / \mathrm{P}$ & $\mathrm{A} / \mathrm{A}$ \\
\hline TM-2420/TM-2020 & Osc & At rest & $\mathrm{F} / \mathrm{F}$ & $\mathrm{D} / \mathrm{D}$ \\
\hline TM-2420 Model 5 & Osc & At rest & $\mathrm{P} / \mathrm{P}$ & $\mathrm{C} / \mathrm{C}$ \\
\hline TM-2420 Model 6 & Osc & At rest & $\mathrm{P} / \mathrm{P}$ & $\mathrm{B} / \mathrm{B}$ \\
\hline TM-2420 Model 7 & Osc & At rest & $\mathrm{P} / \mathrm{P}$ & $\mathrm{B} / \mathrm{B}$ \\
\hline \multirow[t]{2}{*}{ TM 2421 - Takeda 2421} & Aus & In children (different posture) & & $\mathrm{A} / \mathrm{B}$ \\
\hline & Osc & & & $\mathrm{C} / \mathrm{C}$ \\
\hline Takeda 2430 & Osc & At rest & $\mathrm{P} / \mathrm{P}$ & $\mathrm{A} / \mathrm{A}$ \\
\hline
\end{tabular}

${ }^{\star}$ Osc $=$ oscillometric; Aus=auscultatory.

†Criteria for the fulfilment of the AAMI protocol: mean (SD) difference with auscultatory measurements $\leqslant 5(\leqslant 8) \mathrm{mm} \mathrm{Hg} ; \mathrm{P} / \mathrm{P}=$ passed; $\mathrm{F} / \mathrm{F}=$ failed; $\mathrm{P} / \mathrm{F}=$ passed for systolic pressure but failed for diastolic pressure.

‡Grades A-D according to the BHS protocol: A, D=best, worst agreement with mercury standard; according to the BHS protocol devices must achieve at least grade $\mathrm{B} / \mathrm{B}$. within subject coefficient of variation was significantly smaller for the night time blood pressure than for the daytime blood pressure $(8.7 \%(3.6 \%)$ v $10.4 \%(3.3 \%) ; \mathrm{p}<0.0001)$ is in line with this hypothesis. ${ }^{47}$ An additional explanation for the close correlation between cardiovascular risk and the night time blood pressure could be that both are linked to a common pathophysiological mechanismsuch as a raised sympathetic tone ${ }^{106}$ or renal dysfunction - necessitating a higher night time blood pressure to sustain natriuresis. ${ }^{107}$

Patients with secondary hypertension usually have a considerably increased blood pressure, but their diurnal profile is often flattened or even inverted. ${ }^{108-111}$ Although not a very sensitive test, when ambulatory monitoring shows severe sustained hypertension, especially in the presence of a non-dipping nocturnal blood pressure, consideration should be given to the possibility of secondary hypertension.

\section{Management of hypertension in special groups}

OLDER PATIENTS

In the Syst-Eur trial systolic blood pressure was on average $22.0 \mathrm{~mm} \mathrm{Hg}$ higher $(\mathrm{p}<0.001)$ on conventional than on daytime ambulatory measurement. ${ }^{47}{ }^{80}$ The corresponding mean \pm 2 SD interval ranged from -8.3 to $+52.3 \mathrm{~mm}$ Hg. ${ }^{47} 80$ These results show that conventional sphygmomanometry, even if repeated at different outpatient visits, may lead to a considerable overestimation of the systolic blood pressure and probably also to excessive treatment of systolic hypertension.

On ambulatory monitoring some older hypertensive patients show striking variability of their diurnal blood pressure with periods of hypotension interspersed with hypertension. This pattern is important to identify so that treatment can be tailored to take account of the fluctuations in blood pressure. In general, older patients are prone to develop hypotension, which may be postural or postprandial ${ }^{112}{ }^{113}$ in nature, may be caused by baroreceptor dysfunction or autonomic failure, ${ }^{114}$ or may be the consequence of the greater susceptibility of elderly people to the adverse effects of drugs to lower blood pressure. The identification of symptomatic hypotension constitutes a priviliged indication for the clinical use of ambulatory monitoring in elderly people (table 3 ). ${ }^{115}$

\section{PREGNANCY}

Several devices for ambulatory monitoring (table 4) have been specifically validated for use in pregnant women. ${ }^{116}{ }^{117}$ As in the non-pregnant state, the main indication for ambulatory monitoring in pregnancy is the measurement of the white coat effect. Its recognition is important so that pregnant women are not given antihypertensive drugs unnecessarily or excessively. Normal values for ambulatory blood pressure in the pregnant population are available $\mathrm{e}^{118119}$ and the changes in blood pressure which occur during the trimesters of pregnancy and in the postpartum period have been defined. ${ }^{119}$ The evidence that ambulatory blood pressure monitoring may 
predict pre-eclamptic toxaemia is not yet conclusive. ${ }^{120-122}$ On the other hand, hypertension in pregnancy, as diagnosed with ambulatory monitoring, has been shown to be associated with infants of lower birth weight than in normotensive women. ${ }^{123}$

\section{Self recorded blood pressure}

The development of relatively cheap and properly validated devices stimulated the clinical application of self measurement of blood pressure. ${ }^{124-128}$ Blood pressure variation through the whole day can only be monitored by ambulatory measurement, but several advantages of that approach can also be accomplished by self measurement. ${ }^{129} 130$ The greater number of readings, ${ }^{127} 131$ which can be obtained in a practical way, and the absence of the white coat effect ${ }^{132}$ contribute to a better diagnostic accuracy compared with conventional sphygmomanometry. ${ }^{103} 133134$ Furthermore, self measurement of blood pressure has been shown to increase compliance to prescribed drugs, ${ }^{135136}$ and to reduce the number of clinic visits required for the diagnosis and treatment of hypertension. ${ }^{137-139}$ If automated devices are used, ${ }^{127}$ self recorded blood pressure values are also free of observer bias.

The widespread clinical use of self measurement is still limited by the lack of a generally accepted reference frame and operational thresholds for initiating and adjusting antihypertensive treatment. A meta-analysis of the summary statistics of published articles showed that self recorded blood pressure averaged 115/71 $\mathrm{mm} \mathrm{Hg}$ in normotensive people and $119 / 74 \mathrm{~mm}$ $\mathrm{Hg}$ in untreated subjects not selected on the basis of their blood pressure. ${ }^{13}$ In an international database of self recorded blood pressures, ${ }^{140}$ the 95 th percentile in 2401 normotensive people was $136 / 85 \mathrm{~mm} \mathrm{Hg}$ for the measurements taken in the morning, 139/86 $\mathrm{mm} \mathrm{Hg}$ for the measurements obtained in the evening, and $137 / 85 \mathrm{~mm} \mathrm{Hg}$ for the self recorded blood pressure regardless of the time of day. This meta-analysis concluded that a self recorded blood pressure above $137 \mathrm{~mm} \mathrm{Hg}$ systolic or 85 $\mathrm{mm} \mathrm{Hg}$ diastolic should be considered hypertensive. These thresholds are in close agreement with those for the daytime ambulatory blood pressure (table 2) and with other proposals for self recorded measurements. ${ }^{13}{ }^{54}{ }_{141-143}$ However, they must be further validated in clinical trials and prospective outcome studies.

Few studies with the goal to validate self recorded blood pressure measurements for cardiovascular risk have been published. In a prospective Japanese population study, the self recorded blood pressure had a stronger predictive power for subsequent mortality than the screening blood pressure. ${ }^{144}$ Mancia et al ${ }^{101}$ found that ambulatory blood pressure measurements correlated better with regression of left ventricular hypertrophy in hypertensive patients than did clinic and self recorded blood pressure measurements. However, in this study ${ }^{101}$ the self recorded blood pressure was measured on only one day, once in the morning and once in the evening. Had the self recorded blood pressure been taken over many days, the results might have been different. The treatment of hypertension according to the home or office blood pressure (THOP) trial ${ }^{145}$ is currently investigating whether antihypertensive treatment guided by the self measured blood pressure would be more beneficial and cost effective than treatment based on conventional sphygmomanometry.

\section{Choice of devices}

Most of the automated blood pressure measuring devices manufactured for use in ambulatory conditions (table 4) or at home use either an auscultatory or an oscillometric method, or a combination of both techniques. ${ }^{146}$ The oscillometric, compared with the auscultatory technique, has the advantage of being less costly from an engineering point of view and requires less complex algorithms. Oscillometry can be used in noisy surroundings, such as factories. The oscillometric technique provides readings when an auscultatory gap is present, when the Korotkoff sounds persist until zero pressuresuch as in patients with hyperkinetic circulation $^{147}$ - or when the sounds are faintsuch as in obese subjects. The position of the microphone(s) is a source of error specific to the auscultatory approach. ${ }^{147}$ Both methods of measurement, however, are equally affected by dysrhythmias and artifacts of motion. ${ }^{148} \mathrm{~A}$ few devices measure pressure simultaneously by auscultation and oscillometry. ${ }^{148} 149$ They provide the means to compare the two techniques in similar conditions. ${ }^{149}$ Standard auscultatory readings may be supplemented by oscillometric measurements, whenever the auscultatory cannot be successfully completed, or vice versa. ${ }^{149}$

Most, if not all, manufacturers of monitoring devices refuse to disclose the proprietary algorithms for measuring blood pressure. Moreover, manufacturers tend to modify the devices and algorithms without prior notice. ${ }^{150-152}$ Particularly for oscillometric devices, which put empirically derived algorithms into practice, this practice is not acceptable. The guidelines of the British Hypertension Society state that when manufacturers incorporate modifications into externally identical or indistinguishable versions of a model, this should be clearly indicated, and that full details on how the new device differs from earlier versions should be provided. ${ }^{153}$ The revision of the British guidelines stressed that it is incumbent upon manufacturers to clearly indicate all modifications in the hardware and software components of automated devices, for instance by changing the device number. ${ }^{153}$ Furthermore, modified devices must be subject to a new validation. ${ }^{153}$

There is general consensus among all guidelines ${ }^{66} 6784$ 154-157 that only properly validated devices ${ }^{146}$ should be used for ambulatory monitoring (table 4) or for the self measurement of blood pressure (Omron HEM-705CP, ${ }^{158}{ }^{159}$ Omron $722 \mathrm{C}^{159}$ or Omron HEM-713C $\left.C^{160}\right)$. The procedures required for the validation have also been thoroughly standardised. ${ }^{153} 157$ 161-163 Devices can only be considered to have passed validation if the test results have been published as full papers in 
peer reviewed journals. ${ }^{153}$ Furthermore, when devices are to be used in special patient populations - such as older subjects or pregnant women ${ }^{116} 117164$-or in special conditions-such as exercise, ${ }^{148} 165$ a specific demonstration of accuracy in these defined subgroups and conditions is necessary. ${ }^{161} 164$

\section{Conclusions}

The technique of non-invasive ambulatory blood pressure monitoring is now well established as an instrument in clinical research and as a diagnostic tool in clinical practice. Self measurement of blood pressure may become a more cost effective alternative to diagnose white coat hypertension in the near future, but cannot provide information on blood pressure during sleep. These automated techniques minimise misclassification of subjects due to the white coat effect and have over the past two decades found wide acceptance in the management of hypertensive patients, ${ }^{98}$ especially in Europe. It is likely that blood pressure measurement in occupational and environmental medicine will follow the same trends as those in clinical medicine.

The Belgian population studies have been supported by the International Lead Zinc Research Organisation (Research Triangle Park, NC, USA), the municipality Hechtel-Eksel (Belgium) gle Park, NC, USA), the municipality Hechtel-Eksel (Belgium)
and the Nationaal Fonds voor Wetenschappelijk Onderzoek and the Nationaal Fonds voor Wetenschappelijk Onderzoek Vlaanderen (Brussels, Belgium). The ambulatory blood pressure and treatment of hypertension (APTH) and the treatment of hypertension according to home or office blood pressure (THOP) trials are conducted under the auspices of the Belgian
Hypertension Committee and are funded by AstraZeneca (BrusHypertension Committee and are funded by AstraZeneca (Brus-
sels, Belgium). The systolic hypertension in Europe (Syst-Eur) trial was a concerted action of the BIOMED Research Programme sponsored by the European Union. The Syst-Eur trial was carried out in consultation with the World Health Organisation, the International Society of Hypertension, the European Society of Hypertension and the World Hypertension League. The trial was sponsored by Bayer AG (Wuppertal, Germany). In preparing this manuscript we gratefully acknowledge the expert assistance of Veerle Boon, Lutgardis Depauw, Yvette Toremans, Inge Van Sylvia Van Hulle, and Renilde Wolfs.

1 Staessen JA, Roels H, Fagard R, for the PheeCad Investigators. Lead exposure and the conventional and ambulatory blood pressure. A prospective population study. $7 A M A$ 1996;275:1563-70.

2 Staessen JA, Roels H, Lauwerys RR, et al. Low-level lead exposure and blood pressure. F Hum Hypertens 1995;9: 303-28.

3 Staessen JA, Bulpitt CJ, Fagard R, et al. Hypertension caused by low-level lead exposure: myth or fact? $\mathcal{F}$ Cardiovasc Risk 1994;1:87-97.

4 Staessen J, Amery A, Bernard A, et al. Blood pressure, the prevalence of cardiovascular diseases and exposure to cadmium: a population study. Am f Epidemiol 1991;134 257-67. 5 Whittemore AS, DiCiccio Y, Provenzano G. Urinary
cadmium and blood pressure: results from the NHANES II survey. Environ Health Perspect 1991;91:133-40.

6 Staessen JA, Kuznetsova T, Roels HA, et al. Environmental exposure to cadmium and conventional and ambulatory blood pressures in a prospective population study. $A m \mathcal{F}$ Hypertens 2000;13:146-56.

7 Schnall PL, Pieper C, Schwartz JE, et al. The relationship between job strain, workplace diastolic blood pressure, and between job strain, workplace diastolic blood pressure, a
left ventricular mass index. $¥ A M A$ 1990;263:1929-35.

8 Staessen JA, Poulter NR, Fletcher AE, et al. PsychoStaessen JA, Poulter NR, Fletcher AE, et al. Psychoemotional stress and salt intake may interact

pressure. $\mathcal{F}$ Cardiovasc Risk 1994;1:45-51.
9 Arabidze GG, Petrov V, Staessen JA. Blood pressure by Korotkoff's auscultatory method: end of an era or bright future? Blood Pressure Monitoring 1996;1:321-7.

10 Amery A, Brunner HR, Clement DI, et al. Consensus document on non-invasive ambulatory blood pressure monitoring. F Hypertens $1990 ; 8$ (suppl 6):135-40.

11 Pickering TG, O'Brien ET. Second international consensus meeting on twenty-four-hour blood pressure measurement: consensus and conclusions. I Hypertens 1991;9(supp 8):S2-6.

12 Staessen JA, Fagard R, Thijs L, et al. The Fourth International Consensus Conference on 24-Hour Ambulatory Blood Pressure Monitoring: a consensus view on the technique of ambulatory blood pressure monitoring. technique of ambulatory b

13 Thijs L, Staessen JA, Celis H, et al. Reference values for selfrecorded blood pressure. A meta-analysis of summary data. Arch Intern Med 1998;158:481-8.
14 O'Brien E, O'Malley K. Techniques for measuring blood pressure and their interpretation. In: Birkenhäger WH, ed. Practical management of hypertension. Dordrecht, The Netherlands: Kluwer, 1990:1-24.

15 O'Brien E, O'Malley K. Clinical blood pressure measurement. In: Robertson JIS, ed. Clinical hypertension. Amsterdam, The Netherlands: Elsevier, 1992:14-50.

16 Raftery EB, Ward AP. The indirect method of recording blood pressure. Cardiovasc Res 1968;2:210-18.

17 Pickering TG, C Pieper, CB Schechter. Ambulatory monitoring and blood pressure variability. London: Science Press, 1991:2.1-2.16.

18 Rose GA, Holland WW, Crowley EA. Observer factors in the measurement of blood pressure. Nurs Res 1961;10:4-17.

19 Patterson HR. Sources of error in recording the blood pressure of patients with

20 Sassano P, Chatellier G, Corvol P, et al. Influence of observer's expectation on the placebo effect in blood pressure trials. Curr Ther Res 1987;41:305-12.

21 Mancia G, Ferrari A, Gregorini L, et al. Blood pressure and heart rate variabilities in normotensive and hypertensive human beings. Circ Res 1983;53:96-104

22 Pickering TG, James GD, Boddie C, et al. How common is white coat hypertension? fAMA 1988;259:225-8

23 Verdecchia P, Schillaci G, Boldrini F, et al. Variability between current definitions of normal ambulatory blood pressure. Implications in the assessment of white coat hypertension. Hypertension 1992;20:555-62.

24 Mancia G, Bertinieri G, Grassi G, et al. Effects of blood pressure measurement by the doctor on patient's blood pressure and heart rate. Lancet 1983;ii:695-8.

25 Mancia G, Parati G, Pomidossi G, et al. Alerting reaction and rise in blood pressure during measurement by physician and nurse. Hypertension 1987;9:209-15.

26 Armitage P, Rose GA. The variability of measurements of casual blood pressure. I. A laboratory study. Clin Sci 1966; 30:325-35.

27 Bevan AT, Honour AJ, Stott FH. Direct arterial pressure recording in unrestricted man. Clin Sci 1969;36:329-44.

28 Pickering TG, Harshfield GA, Kleinert HD, et al. Blood pressure during normal daily activities, sleep, and exercise. Comparison of values in normal and hypertensive subjects. ҰAMA 1982;247:992-6.

29 Harlan WR, Landis JR, Schmouder RL, et al. Blood lead and blood pressure. Relationship in the adolescent and US population. FAMA 1985;253:530-4

30 Pirkle JL, Schwartz J, Landis JR, et al. The relationship between blood lead levels and blood pressure and its cardiovascular complications. Am f Epidemiol 1985;121: 246-58.

31 Rabinowitz M, Bellinger D, Leviton A, et al. Pregnancy hypertension, blood pressure during labor, and blood lead levels. Hypertension 1987;10:447-51. 32Plan and operation of the 3rd national health and nutrition examination survey, 1988-94. Washington DC, USA: National Center for Health Statistics, Centers for Disease Control and Preven-
tion, Public Health Service, US Department of Health and tion, Public Health Service,
Human Services, 1994:5-6.

33 MacMahon S, Peto R, Cutler J, et al. Blood pressure, stroke, and coronary heart disease. Part 1, prolonged differences in blood pressure: prospective observational studies corrected for the regression dilution bias. Lancet 1990;335:765-74.

34 Gardner MJ, Heady JA. Some effects of within-person variability in epidemiologic studies. F Chron Dis 1973;26: 781-93.

35 Staessen J, O'Brien E, Atkins N, et al. The increase in blood pressure with age and body mass index is overestimated by 136:450-9.

36 The Scientific Committee. Consensus document on noninvasive ambulatory blood pressure monitoring. F Hypertens 1990;8(suppl 6):S135-40.

37 Petrie JC, O'Brien ET, Littler WA, et al. Recommendations on blood pressure measurement by a working party of the British Hypertension Society. BMF 1989;293:611-15.

38 Conway J, Johnston J, Coats A, et al. The use of ambulatory blood pressure monitoring to improve the accuracy and to reduce the number of subjects in clinical trials of antihypertensive agents. F Hypertens 1988;6:111-16.

39 Verdecchia P, Schillaci G, Borgioni C, et al. Prognostic significance of the white coat effect. Hypertension 1997;29: $1218-24$

40 Kannel WB. Blood pressure as a cardiovascular risk factor: prevention and treatment. $\mathcal{F A M A}$ 1996;275:1571-6.

41 Stamler J. Blood pressure and high blood pressure: aspects of risk. Hypertension 1991;18(suppl I):95-107.

42 Staessen JA, Fagard RH, Lijnen PJ, et al. Mean and range of the ambulatory blood pressure in normotensive subjects from a meta-analysis of 23 studies. Am $\mathcal{F}$ Cardiol 1991;67:723-7.

43 James GD, Moucha OP, Pickering TG. The normal hourly variation of blood pressure in women: average patterns and the effect of work stress. F Hum Hypertens 1991;5:505-9.

44 O'Brien E, Murphy J, Tyndall A, et al. Twenty four hour ambulatory blood pressure in men and women aged 17-80 60

45 Staessen JA, O'Brien ET, Amery AK, et al. Ambulatory blood pressure in normotensive and hypertensive subjects: results from an international database. $\mathcal{f}$ Hypertens 1994;12 (suppl 7):S1-12.

46 Mancia G, Omboni S, Ravogli A, et al. Ambulatory blood pressure monitoring in the evaluation of antihypertensive 
treatment: additional information from a large data base. Blood Pressure 1995;4:148-59.

47 Staessen JA, Thijs L, Fagard R, et al. Predicting cardiovascular risk using conventional $v$ ambulatory blood pressure in older patients with systolic hypertension. $\mathcal{F} A M A$
1999;282:539-46.

48 Nakatsuka H, Imai Y, Abe K, et al. Population study of ambulatory blood pressure in a rural community in northern Japan. Tohoku $\mathcal{F}$ Exp Med 1991;163:119-27.

49 Imai Y, Nagai K, Sakuma M, et al. Ambulatory blood pressure of adults in Ohasama, Japan. Hypertension 1993;22 $900-12$.

50 Staessen J, Bulpitt CJ, O'Brien E, et al. The diurnal blood pressure profile. A population study. Am $\mathcal{F}$ Hypertens 1992; 5:386-92.

51 Staessen J, Bulpitt CJ, Fagard R, et al. Reference values for the ambulatory blood pressure and the blood pressure measured at home: a population study. 7 Hum Hypertens 1991;5:355-61.

52 Staessen JA, Fagard R, Lijnen P, et al. Ambulatory blood pressure and blood pressure measured at home: progress report on a population study. $\mathcal{F}$ Cardiovasc Pharmacol 1994 23(suppl 5):S5-11.

53 Imai Y, Munakata M, Hashimoto J, et al. Age-specific characteristics of nocturnal blood pressure in a general population in a community of northern Japan. Am $\mathcal{f}$ Hypertens 1993;6:179S-83S.

54 Sega R, Bravi C, Cesana G, et al. Ambulatory and home blood pressure normality: the PAMELA study. $\mathcal{F}$ Cardiovasc Pharmacol 1994;23(suppl 5):S12-15.

55 Cesana G, De Vito G, Ferrario M, et al. Ambulatory blood pressure normalcy: the PAMELA study. $\mathcal{F}$ Hypertens 1991; 9(suppl 3):S17-23.

56 Staessen JA, Bieniaszewski L, O'Brien ET, et al. An epidemiological approach to ambulatory blood pressure monitoring: the Belgian population study. Blood Pressure Monitoring 1996;1:13-26.

57 Wiinberg N, Hoegholm A, Christensen HR, et al. 24 Hour ambulatory blood pressure in 352 normal Danish subjects, related to age and gender. Am F Hypertens 1995;8:978-86.

58 Mancia G, Sega G, Bravi C, et al. Ambulatory blood pressure normality: results from the PAMELA study. $\mathcal{F}$ Hypertens 1995;13:1377-90.

59 Staessen JA, Bieniaszewski L, O’Brien E, et al. Nocturnal blood pressure fall on ambulatory monitoring in a large international database. Hypertension 1997;29:30-9.

60 Mancia G, Sega R, Milesi C, et al. Blood-pressure control in the hypertensive population. Lancet 1997;349:454-7.

61 Sega R, Cesana G, Milesi C, et al. Ambulatory and home blood pressure normality in the elderly: data from the PAMELA population. Hypertension 1997;30(part 1):1-6.

62 Staessen J, O'Brien ET, Atkins N, et al. Short report: ambulatory blood pressure in normotensive compared with latory blood pressure in normotensive compared

63 Staessen J, Fagard R, Lijnen P, et al. Reference values for ambulatory blood pressure: a meta-analysis. $\mathcal{F}$ Hyperten 1990;8(suppl 6):S57-64.

64 Imai Y, Satoh H, Nagai K, et al. Characteristics of a community-based distribution of home blood pressure in Ohasama in northern Japan. F Hypertens 1993;11:1441-9.

65 Staessen JA, Bieniaszewski L, O'Brien ET, et al. What is a normal blood pressure on ambulatory monitoring? Nephrol Dial Transplant 1996;11:241-5.

66 Guidelines Subcommittee. 1999 World Health Organization-International Society of Hypertension guidelines for the management of hypertension. $f$ Hypertens 1999; 17:151-83.

67 The Joint National Committee on Prevention Detection Evaluation and Treatment of High Blood Pressure. The Evaluation and Treatment of High Blood Pressure. The
6th report of the Joint National Committee on Prevention, 6th report of the Joint National Committee on Prevention,
Detection, Evaluation, and Treatment of High Blood PresDetection, Evaluation, and Treatment of
sure. Arch Intern Med 1997;157:2413-46.

68 Verdecchia P, Porcellati C, Schillaci G, et al. Ambulatory blood pressure. An independent predictor of prognosis in essential hypertension. Hypertension 1994;24:793-801.

69 Devereux RB, James GD, Pickering TG. What is norma blood pressure? Comparison of ambulatory pressure level and variability in patients with normal or abnormal lef ventricular geometry. Am f Hypertens 1993;6:211S-15.

70 Koren MJ, Devereux RB, Casale PN, et al. Relation of left ventricular mass and geometry to morbidity and mortality in uncomplicated essential hypertension. Ann Intern Med 1991;114:345-52.

71 Gosse P, Promax H, Durandet P, et al. White coat hypertension. No harm for the heart. Hypertension 1993;22. 766-70.

72 Perloff D, Sokolow M, Cowan R. The prognostic value of ambulatory blood pressures. $\mathcal{F} A M A$ 1983;249:2792-8

73 Perloff D, Sokolow M, Cowan RM, et al. Prognostic value of ambulatory blood pressure measurements: further analyses. F Hypertens 1989;7(suppl 3):S3-10.

74 Mann S, Millar Craig MW, Raftery EB. Superiority of 24-hour measurement of blood pressure over clinic values in determining prognosis in hypertension. Clin Exp Hypertens 1985;A7:279-81.

75 Khattar RS, Senior R, Lahiri A. Cardiovascular outcome in white coat versus sustained mild hypertension. A 10 year follow up study. Circulation 1998;98:1892-7.

76 Ohkubo T, Imai Y, Tsuji I, et al. Reference values for 24 hour ambulatory blood pressure monitoring based on a prognositic criterion. The Ohasama study. Hypertension 1998;32:255-9.

77 Ohkubo T, Imai Y. Correspondence in reaction to: Staessen JA, Thijs L, Fagard R, et al. Predicting cardiovascular risk using conventional $v$ ambulatory blood pressure in older patients with systolic hypertension (JAMA 1999;282:53946). ҒAMA 2000;283:475-6.

78 Redón J, Campos C, Narciso ML, et al. Prognostic value of ambulatory blood pressure monitoring in refractory hypertension. A prospective study. Hypertension 1998;31:712-18.

79 Staessen J, Amery A, Clement D, et al. Twenty-four hour blood pressure monitoring in the Syst-Eur trial. Aging in Clinical and Experimental Research 1992;4:85-91.

80 Emelianov D, Thijs L, Staessen JA, et al. Conventional and ambulatory blood pressure measurement in older patients the Syst-Eur trial. Blood Pressure Monitoring 1998;3:17380 .

81 Amery A, Birkenhäger W, Bulpitt CJ, et al. Syst-Eur. A multicentre trial on the treatment of isolated systolic hypertension in the elderly: objectives, protocol and organisation. Aging in Clinical and Experimental Research 1991;3:287302 .

82 Staessen JA, Fagard R, Thijs L, et al. Randomised double-blind comparison of placebo and active treatment for older patients with isolated systolic hypertension. Lancet 1997;350:757-64.

83 Staessen JA, Fagard R, Thijs L, et al. Subgroup and per-protocol analysis of the randomized European trial on isolated systolic hypertension in the elderly. Arch Intern Med 1998;158:1681-91.

84 Pickering TG. A review of national guidelines on the clinical use of ambulatory blood pressure monitoring. Blood Pressure Monitoring 1996;1:151-6.

85 Staessen J, Amery A, Fagard R. Editorial review. Isolated systolic hypertension. F Hypertens 1990;8:393-405.

86 Palatini P, Pessina AC. A new approach to define the upper normal limits of ambulatory blood pressure. 7 Hypertens 1990;8(suppl 6):S65-70.

87 Staessen JA, Byttebier G, Buntinx F, et al. Antihypertensive treatment based on conventional or ambulatory blood pressure measurement. A randomized controlled trial. FAMA 1997;278:1065-72.

88 Owens PE, Lyons SP, Rodriguez SA, et al. Is elevation of clinic blood pressure in patients with white coat hypertension who have normal ambulatory blood pressure associated with target organ changes? f Hum Hypertens 1998;12:743-8.

89 Sokolow M, Lyon TP. The ventricular complex in left ventricular hypertrophy as obtained by unipolar precordial and limb leads. Am Heart f 1949:37;161-86.

90 Julius S, Mejia A, Jones K, et al. "White coat" versus sustained" borderline hypertensio

et al. Is white coat hypertension innocent? Structure and function of the heart in the elderly. Hypertension 1993;22:826-31.

92 Nalbantgil I, Onder R, Nalbantgil S, et al. The prevalence of silent myocardial ischaemia in patients with white-coat hypertension. F Hum Hypertens 1998;12:337-41.

93 Mancia G, Zanchetti A. White-coat hypertension: misnomers, misconceptions and misunderstandings. What should we do next? F Hypertens 1996;14:1049-52.

94 Fagard R, Bielen E, Staessen J, et al. Response of ambulatory blood pressure to antihypertensive therapy guided by clinic pressure. Am f Hypertens 1993;6:648-53.

95 Pickering TG. White coat hypertension. Curr Opin Nephrol Hypertens 1996;5:192-8.

96 Fitscha P, Meisner W. Indications for antihypertensive treatment: superiority of ambulatory $v$ casual blood pressure measurement. Blood Press 1994;3:36-9.

97 Staessen J, Amery A. APTH: a trial on ambulatory blood pressure monitoring and treatment of hypertension: objecpressure monitoring and treatment of hypertension: o

98 Staessen JA, Beilin L, Parati G, et al. Task force IV: clinical use of ambulatory blood pressure monitoring. Blood Pressure Monitoring 1999;4:319-31

99 Pickering TG. White coat hypertension: time for action. Circulation 1998;97:1834-6.

00 Bidlingmeyer I, Burnier M, Bidlingmeyer M, et al. Isolated office hypertension: a prehypertensive state? 7 Hypertens 1996;14:327-32.

101 Mancia G, Zanchetti A, Agebiti-Rosei E, et al. Ambulatory blood pressure is superior to clinic blood pressure in predicting treatment-induced regression of left ventricular hypertrophy. Circulation 1997;95:1464-70.

102 Fagard RH, Staessen JA, Thijs L. Relationships between changes in left ventricular mass and in clinic and ambulatory blood pressure in response to antihypertensive therapy. F Hypertens $1997 ; 15$ (part 1):1493-502.

103 Pickering T, for an American Society of Hypertension Ad Hoc Panel. Recommendations for the use of home (self) and ambulatory blood pressure monitoring. Am $\mathcal{f}$ Hypertens 1995;9:1-11.

104 O'Brien E, Sheridan J, O'Malley K. Dippers and non-dippers. Lancet 1988;ii:397.

05 Fagard R, Staessen JA, Thijs L. The relationships between left ventricular mass and daytime and night-time blood pressures: a meta-analysis of comparative studies. F Hypertens 1995;13:823-9.

106 Dodt C, Breckling U, Derad I, et al. Plasma epinephrine and norepinephrine concentrations of healthy humans associated with nighttime sleep and morning arousal. Hypertension 1997;30(part 1):71-6.

107 Staessen JA, Birkenhäger W, Bulpitt CJ, et al. The relationship between blood pressure and sodium and potassium excretion during the day and at night. F Hypertens 1993;11: $443-7$. 
108 Imai Y, Abe K, Sasaki S, et al. Altered circadian blood pressure rhythm in patients with Cushing's syndrome. Hypertension 1988;12:11-19.

109 Imai Y, Abe K, Sasaki S, et al. Circadian blood pressure variation in patients with renovascular hypertension in primary aldosteronism. Clin Exp Hypertens 1992;A14:114167.

110 Middeke M, Mika E, Schreiber MA, et al. Ambulante indirekte Blutdrucklangzeitmessung bei primärer un sekundärer Hypertonie. Klinische Wochenschrift 1989;67: 713-16.

111 Middeke M, Schrader J. Nocturnal blood pressure in normotensive subjects and those with white coat, primary, and secondary hypertension. BMF 1994;308:630-2.

112 Grodzicki T, Rajzer M, Fagard R, et al. Ambulatory blood pressure monitoring and postprandial hypotension in elderly patients with isolated systolic hypertension. $7 \mathrm{Hum}$ Hypertens 1998;12:161-5.

113 Kohara K, Uemura K, Takata Y, et al. Postprandial hypotension: evaluation by ambulatory blood pressure hypotension: evaluation by ambulatory blood

114 Ikeda T, Matsubara T, Sato Y, et al. Circadian blood pressure variation in diabetic patients with autonomic neuropathy. F Hypertens 1993;11:1139-40.

115 Mallion JM, Baguet JP, Noirclerc M, et al. Blood pressure measurement in other illnesses and hypotension: usefulness of ambulatory measures of blood pressure measurements. Blood Pressure Monitoring 1996;1 (suppl 2):S19-26.

116 Clark SJ, Hofmeyr GJ, Coats AJS, et al. Ambulatory blood pressure monitoring during pregnancy: validation of the TM-2420 monitor. Obstet Gynecol 1991;77:152-5.

117 O'Brien E, Mee F, Atkins N, et al. Accuracy of the SpaceLabs 90207 blood pressure measuring system in normotensive pregnant women determined by the British Hypertension Society protocol. F Hypertens 1993;11(suppl 5):S282-3

118 Siamopoulos KC, Papanikolaou S, Elisaf M, et al. Ambulatory blood pressure monitoring in normotensive pregnant tory blood pressure monitoring in normo

119 Halligan A, O’Brien E. Ambulatory blood pressure monitoring during pregnancy: establishment of standards of toring during pregnancy: establishment

120 Penny JA, Shennan AH, Halligan AW, et al. Blood pressure measurement in severe pre-eclampsia. Lancet 1997;349: 1518.

121 Hermida RC, Ayala DE. Diagnosing gestational hypertension and pre-eclampsia with the 24 hour mean of blood pressure. Hypertension 1997;30:1531-7.

122 Hermida RC, Ayala DE, Mojon A, et al. Blood pressure excess for the early identification of gestational hyper-
tension and pre-eclampsia. Hypertension 1998;31:83-9.

123 Churchill D, Perry IJ, Beevers DG. Ambulatory blood $7-10$

124 De Cesaris R, Ranieri G, Andriani A, et al. Comparison of two angiotensin converting enzyme inibitors with different pharmacokinetics alone or combined with a diuretic on 24-hour blood pressure levels. Curr Ther Res 1991;50:59924-hos.

125 Pessina AC. Home blood pressure monitoring in the elderly. Cardiology of the Elderly 1993;1:494-9.

126 Van Egmond J, Lenders JWM, Weernink E, et al. Accuracy and reproducibility of 30 devices for self measurement of arterial blood pressure. Am f Hypertens 1993;6:873-9.

127 Stergiou GS, Skeva II, Zourbaki AS, et al. Self monitoring of blood pressure at home: how many measurements are needed? f Hypertens 1998;16:725-31.

128 Stergiou GS, Voutsa AV, Achimastos AD, et al. Home self monitoring of blood pressure. Is fully automated oscillometric technique as good as conventional stethoscopic technique? Am f Hypertens 1997;10:428-33.

129 Soghikian K, Casper SM, Fireman BH, et al. Home blood pressure monitoring. Effect on use of medical services and medical care costs. Med Care 1992;30:855-65.

130 Celis H, De Cort P, Fagard R, et al. For how many days should blood pressure be measured at home in older patients before steady levels are obtained? F Hum Hypertens patients before

131 Conway J. Home blood pressure recording. Clin Exp Hypertens 1986;8:1247-94.

132 Fagard R, Staessen J, Thijs L. Ambulatory blood pressure during antihypertensive therapy guided by conventional pressure. Blood Pressure Monitoring 1996;1:279-81.

133 O'Brien E, Fitzgerald D, O'Malley K. Comparison of clinic, home and ambulatory blood pressure measurement. fournal of Ambulatory Monitoring 1988;1:285-91.

134 Cottier C, Julius S, Gajendragadkar SV, et al. Usefulness of home $\mathrm{BP}$ determination in treating borderline hypertension. $\mathcal{F} A M A$ 1982;248:555-8.

135 Evans CE, Haynes RB, Goldsmith CH, et al. Home blood pressure-measuring devices: a comparative study of accuracy. $\mathcal{F}$ Hypertens 1989;7:133-42.

136 Carnahan JE, Nugent CA. The effects of self-monitoring by patients on the control of hypertension. $\mathrm{Am} \mathcal{F} \mathrm{Med} \mathrm{Sci}$ 1975;269:69-73.

137 Chatellier G, Dutrey-Dupagne C, Vaur L, et al. Home self blood pressure measurement in general practice. The blood pressure measurement in general practic
SMART Study. Am f Hypertens 1996;9:644-52.

138 Rademaker M, Lindsay BA, McLaren JA, et al. Home monitoring of blood pressure: usefulness as a predictor of monitoring of blood pressure: usefulness as a predicte

139 Wilson MD. Hypertension management in managed care: the role of home blood pressure monitoring. Blood Pressure Monitoring 1997;2:201-6.
140 Thijs L, Staessen JA, Celis H, et al. The international database of self-recorded blood pressures in normotensive and untreated hypertensive subjects. Blood Pressure Monitoring 1999;4:77-86.

141 De Gaudemaris R, Chau NP, Mallion JM, et al. Home blood pressure: variability, comparison with office readings and proposal for reference values. F Hypertens 1994;12: 831-8.

142 Tsuji I, Imai Y, Nagai K, et al. Proposal of reference values for home blood pressure measurement. Prognostic criteria based on a prospective observation of the general population in Ohasama, Japan. Am f Hypertens 1997;10: 409-18.

143 Mejia A, Julius S, Jones KA, et al. The Tecumseh blood pressure study. Normative data on blood pressure selfdetermination. Arch Intern Med 1990;150:1209-13.

144 Ohkubo T, Imai Y, Tsuji I, et al. Home blood pressure measurement has a stronger predictive power for mortality than does screening blood pressure measurement: a population-based observation in Ohasama, Japan. 7 Hypertens 1998;16:971-5.

145 Celis H, Staessen JA, Buntinx F, et al. Antihypertensive treatment based on home or office blood pressure measurement: protocol of the randomized controlled 1):S29-35.

146 O'Brien E, Atkins N, Staessen J. State of the market. A review of ambulatory blood pressure monitoring devices. Hypertension 1995;26:835-42.

147 Palatini P, Penzo M, Canali C, et al. Validation of the A\&D TM-2420 model 7 for ambulatory blood pressure monitoring and effect of microphone replacement on its performance. Fournal of Ambulatory Monitoring 1991;4:281-8.

148 White WB, Lund-Johansen P, Omvik P. Assessment of four ambulatory blood pressure monitors and measurements by clinicians versus intraarterial blood pressure at rest and during exercise. Am F Cardiol 1990;65:60-6.

149 Imai Y, Sasaki S, Minami N, et al. The accuracy and performance of the A\&D TM 2421, a new ambulatory blood pressure monitoring device based on the cuffoscillometric method and the Korotkoff sound technique. Am 7 Hypertens 1992;5:719-26.

150 Hansen KW, Orskov H. A plea for consistent reliability in ambulatory blood pressure monitors: a reminder. $\mathcal{F}$ Hypertens 1992;10:1313-15.

51 O'Brien E, Mee F, Atkins N, et al. Accuracy of the Takeda TM-2420/TM-2020 determined by the British Hypertension Society protocol. F Hypertens 1991;9(suppl 5):S1723

152 O'Brien E, O'Malley K, Atkins N, et al. A review of validation procedures for blood pressure measuring devices. In: Waeber B, O'Brien E, O'Malley K, et al, eds. 24 Hour blood pressure monitoring in clinical practice. New York, USA: Raven, 1994:1-32

153 O'Brien E, Petrie J, Littler W, et al. The British Hypertension Society protocol for the evaluation of automated and semi-automated blood pressure measuring devices with special reference to ambulatory systems. $\mathcal{f}$ Hypertens 1990;8:607-19.

154 O’Brien ET, Pickering TC, van Montfrans GA, et al. Task Force I: methodological aspects. Blood Pressure Monitoring 1999;4:295-302.

155 White WB, Asmar R, Imai Y, et al. Task Force VI: self monitoring of the blood pressure. Blood Pressure Monitoring 1999;4:343-51.

156 White WB. Guidelines on the clinical utility of ambulatory blood pressure. Blood Pressure Monitoring 1998;3:181-4.

157 O'Brien E, Coats A, Owens P, et al. British Hypertension Society recommendations on the use and interpretation of ambulatory blood pressure monitoring. BMF 2000;320:

158 O'Brien E, Mee F, Atkins N, et al. Evaluation of three devices for self-measurement of blood pressure according to the revised British Hypertension Society protocol: the Omron HEM-705 CP, Philips HP5332 and Nissei DS-175. Blood Pressure Monitoring 1996;1:55-62.

159 Bortolotto LA, Henry O, Hanon O, et al. Validation of two devices for self-measurement of blood pressure by elderly patients according to the revised British Hypertension Society protocol: the Omron HEM-722C and HEM735C. Blood Pressure Monitoring 1999;4:21-5.

160 Mufunda J, Sparks B, Chifamba J, et al. Comparison of the Omron HEM-713C automated blood pressure monitor with a standard auscultatory method using a mercury manometer. Cent Afr F Med 1996;42:230-2.

61 O'Brien E, Petrie J, Littler W, et al. Short report: an outline of the revised British Hypertension Society protocol for the evaluation of blood pressure measuring devices. $\mathcal{F}$ Hypertens 1993;11:677-9.

162 White WB, Berson AS, Robbins C, et al. National standard for measurement of resting and ambulatory blood pressures with automated sphygmomanometers. Hypertension 1993;21:504-9.

163 American national standard. Electronic or automated sphygmomanometers. 3330 Washington Boulevard, Suite 400, Arlington, VA 22201-4598, USA: Association for the Advancement of Medical Instrumentation, 1993.

164 Coats AJS, Clark SJ. Validation of ambulatory monitors in special populations. Am f Hypertens 1992;5:664-9.

65 Henschel A, De La Vega F, Taylor HL. Simultaneous direct and indirect blood pressure measurements in man at rest and work. F Appl Physiol 1954;5:506-8. 